\title{
Analyzing Appreciative Inquiry as a Model of Change to build Relational Capital
}

\author{
Hassan Ahmed Shah ${ }^{1}$, Muhammad Yasir ${ }^{2}$, Monty Glenn Miller ${ }^{3}$
}

\begin{abstract}
Relational Capital (RC) is referred as intangible asset that an organization acquires while sustaining effective relations with suppliers, customers or business partners. Prior research suggests that enhanced $\mathrm{RC}$ could significantly improve organizational performance. Therefore, for accentuating the role of $R C$ in a manufacturing concern, an organizational development intervention called Appreciative Inquiry (AI) was conducted in this study. The primary objective of this action-oriented study was to develop relational capital, which was identified by respondents as one of their strengths, through the application of appreciative inquiry. The study was carried out by involving 26 participants from procurement and sales departments in 4-D cycle of AI. Post-intervention survey revealed improved $R C$ and more friendly exchanges among stakeholders. Findings of this study would be useful to inform practitioners about the effectiveness of AI and would set new directions for appreciating the strengths of employees and other stakeholders.
\end{abstract}

Keywords: Appreciative inquiry, relational capital, organization development, and action research.

\section{Introduction}

Due to rapidly changing business environment, the survival of firms having no collaborative arrangements with internal and external stakeholders could face serious threats. Researchers as well as practitioners are, therefore, devising mechanisms to improve collaboration and to gain the advantages of relational capital. Prahalad and Ramaswamy (2000), and Gibbert, Leibold, and Voelpel (2001) advocated that relational capital $(\mathrm{RC})$ is an effective source of competence because it helps in renewing the knowledge-base of an organization. RC theory is established on the principle that organizations are not isolated systems, but are open and dependent on the relationships they maintain with their environment (Hormiga, Batista-Canino, \& Sanchez-Medina,

$1 \mathrm{PhD}$ Scholar $a$ and Lecturer b, Department of Management Sciences, a Hazara University, Mansehra, and $b$ Khushal Khan Khattak University, Karak.Email:shahjee_00766@yahoo.com, hassan.shah@kkkuk.edu.pk

2 Associate Professor, Department of Management Sciences, Hazara University, Mansehra.

Email: muhammadyasir@hu.edu.pk

3 President, International Performance Solutions, Ltd. Email: monty@ipsltd.info

\section{ARTICLE HISTORY}

17 Apr, 2019 Submission Received

10 Jun, 2019 First Review

27 Nov, 2019 Second Review

15 Jan, 2020 Third Review

02 Feb, 2020 Accepted 
2011). Thus, RC includes the value generated by developing relationships not only with customers, suppliers, and shareholders but with all the external stakeholders (Martín de Castro, Lopez Saez, \& Navas Lopez, 2004).

Appreciative Inquiry is rapidly gaining popularity as an organizational development intervention and a source of system-wide transformational change due to its strength-based approach (Bushe, 2013). It is a discovery system aimed at: identifying the strengths in an individual, organization, or other resources; exploring ways to leverage these strengths and attributes; and planning and implementing strategies to move forward with the achievement of objectives (Simons \& Havert, 2012). AI helps in engaging employees into a collective process of reframing and generating possible future (Kaye Hart, Conklin, \& Allen, 2008). It also recognizes and reinforces the elements that give existence, vigor, vitality, and distinctiveness to the organization, thereby appreciating the past to channel the future (Somerville \& Farner, 2012).

For the purpose of accentuating the significance of relational capital in manufacturing concerns, in this study we conducted appreciative inquiry in a large-scale cement manufacturing company. The primary objective of this action-oriented study was to develop the RC of a company through the active involvement of company's employees in 4D cycle of AI. In this study, the concept of RC was redefined by participants during the design stage of AI by articulating the practical/contextual facets of RC. This is a unique study in its essences as it introduces the use of appreciative inquiry in a manufacturing sector organization of Pakistan, as very limited studies could be found to have used AI in manufacturing sector organizations in the developing countries even after extensive literature search from standard research databases. $\mathrm{RC}$ has extensively been discussed in the extant literature with the help of diverse methodologies however, the current study is distinctive in its nature as: firstly, it adds to the literature of $\mathrm{AI}$ and RC by combining the two concepts and secondly, it explains with the help of $\mathrm{AI}$ intervention how $\mathrm{RC}$ is perceived by the employees of a manufacturing firm working in a developing country like Pakistan. The primary research question for this intervention-based study is how the existing strength of relational capital could be strengthened further by using appreciative inquiry? While finding answers to this question, the study aims at developing the RC of a company through the active involvement of company's employees in 4D cycle of AI. The study suggests that using AI interventions, relational capital as well as other strengths of organization should be identified and improved by manufacturing sector organizations to gain better competitive position. The study concludes with the managerial as well as research implications and provides practical recommendations to strengthen the relational capital of organization. A few modifications in AI process have also been proposed for the future AI researchers. 


\section{Literature Review}

\subsection{Appreciative inquiry}

The foundations of appreciative inquiry lie in positive organizational scholarship (Bernstein, 2003). AI is all about studying, discovering, and actively searching out the best and already working in an organization. It has been applied and testified as being effective and transformative in many diverse aspects of organizational change and change management (Carter, 2006). AI comprises of an affirmative topic selection stage and 4D cycle (Whitney \& Gibbs, 2006). In affirmative topic selection stage, participants along with intervention team choose those elements of an organization which are working well and then, after converting it into an attractive topic, is used for the 4D cycle of AI (Cooperrider \& Whitney, 2005). According to Somerville and Farner (2012) the transformative 4-D cycle of AI begins with discovery (appreciating what is), which is followed by dream (imagining what could be), then moves onto design (defining what should be), and lastly entails destiny (establishing what will be).

Appreciative inquiry is an organizational research intervention based on action research methodology (Bushe \& Kassam, 2005), which focuses on discovering the positive facets of an organizational event or activity and identifies the mechanisms to enhance or improve them (Boyd \& Bright, 2007; Cram, 2010). Black, Burrello, and Mann (2017) highlighted the importance of AI in building sustainable architecture for the development of leaders. Sim (2019) hinted upon the relational as well as generative and collaborative nature of $\mathrm{AI}$ in the creation of better organizational future.

Appreciative inquiry is an organizational development tool used to manage change imperatives or transformation processes in the corporate sector (Maritz \& Coetzee, 2012). Thus, it can be viewed both as a methodology and as a general way of thinking manifested in methods highlighting practice and action (Pedler \& Burgoyne, 2007). Sorensen, Yaeger and Bengtsson (2003) in their review of literature published in last 20 years on $\mathrm{AI}$, noted after analyzing 350 articles that it has a dramatic impact on the practice of organizational change and has achieved many successes in different organizational settings. By offering new conceptions of knowledge, new discourses of human potential and new directions to address change initiatives, AI could potentially address disillusionment with the past, misperception about the present, and concerns about the future (Somerville \& Farner, 2012). Bushe and Kassam (2005) emphasized the importance of AI because of its focus on changing the way people think instead of the way they practice and facilitate people in organizing themselves on the foundations of their new ideas.

Carlsen, Rudningen, and Mortensen (2014) emphasized the significance of col- 
laborative and co-generative re/search in AI and highlighted the importance of such efforts in the success of organizations. For instance, Ludema, Whitney, Mohr, and Griffen (2003) have listed more than 75 cases which include business organizations, nonprofit organizations, government agencies, and local communities that have engaged in appreciative inquires, and have transformed themselves. The selection of $\mathrm{AI}$ as an OD intervention in this study was inspired by the fact that it engages and appreciates the standpoints of all stakeholders, pinpoints best practices and offers the opportunity to enhance the performance of organizations as identified by Curtis et al. (2017).

\subsection{Relational capital}

Relational capital (RC), an intangible and non-exclusive resource of any organization, entails formal and informal relationship among stakeholders across value chain that influences the organization's activities by creating profit, business value addition, and market competitiveness (Bontis, 1998; Bharadwaj, 2000; Martín de Castro et al., 2004; Nold, 2012). RC literature is grounded in the theory that organizations are deemed not to be closed systems but as systems that are open and dependent on the relations they have with their environment (Hormiga et al., 2011). Thus, the researchers as Prahalad and Ramaswamy (2000), and Gibbert et al. (2001) suggest that relational capital is a new source of competitive advantage for companies because of its potential to renew the overall competencies and rejuvenate the knowledge-base that could prevent them from being obsolete in today's turbulent environment. Researchers such as Delgado (2011), Ahmed, Kristal, and Pagell (2014), and Agostini and Nosella (2017) explained that relational capital aims at establishing, maintaining and developing relationships with the external actors around a firm. This relationship is influenced by factors as brand orientation, marketing capability, collaboration with external partners, and technological reputation.

Moreover, the exchange of information as well as collaboration process between producers and consumers could be made effective by focusing on knowledge and skills of employees and team-members participating in the process of innovation (Cheng \& Huizingh, 2014; Chen, Liu, Chu, \& Hsiao, 2014; Gabrielsson, 2005). Thus, RC includes: effective marketing capabilities allowing firms to address current and future needs of customer (Hsu \& Wang, 2012); acquisition of knowledge from different external sources and its integration in products offered by firm (Hsu \& Fang, 2009); and, investment in brand image which attracts customers and influences their buying behavior (Meritum, 2002; Trotta, Iannuzzi, Cavallaro, \& Dell'Atti, 2011). The relationships, as explained by Lenart-Gansiniec (2016), are binders that keep complementary resources possessed by market partners together, while strengthening their 
competitiveness and innovation. According to them, the foundations of emerging relationships are established by participants' awareness of their resource limitations, and their belief that some processes could be performed more effectively with the cooperation of internal and external stakeholders. A result of this decision on collaboration is effective exploitation of resources for undertaking specific actions as well as goals accomplishment (Kale, Singh \& Perlmutter, 2000; Uzzi \& Lancaster, 2003).

Clercqa and Sapienzab (2006) explained that strength of relational capital is determined by the extent to which exchange involves social interaction, trust, and shared goals or norms. It includes trademark recognition, information about competitors' activities, employee satisfaction, customer loyalty, and healthy relationship with mass media etc. (Bueno et al., 2011). However, to gain competitive advantage, firm must have the ability to convert intangible assets into value and to leverage that value in its market place. Current research suggests that factors such as strategic orientation, strategic renewal (Shah, Yasir, Majid, Yasir, \& Javed, 2019), and networking capabilities (Shah, Yasir, Majid, \& Javed, 2019) are important to enhance a firm's value creation and survival. Hence, relational capital which is the sum of a firm's relationships with all its stakeholders that forms the basis of its market reputation (Bontis, 1999; Lowendahl, 2005; Gogan, Duran, \& Draghici, 2014) has a vital role in achieving competitive advantage (Theoharakis, Sajtos, \& Hooley, 2009). Furthermore, a recent study by Agostini and Nosella (2017) proved that radical innovation could also be brought into business processes through efficient utilization of relational capital. Similarly, Datta and De (2017) concluded that relational capital has a significant impact on the firm's financial performance.

\subsection{Appreciative inquiry and relational capital}

In view of the literature cited above, $\mathrm{RC}$ could be explained as the value generated by relationships not only with customers but also with suppliers, shareholders and other stakeholders. The process of AI and its underlying principles help in understanding various organizational phenomena especially relational capital (Stavros, Godwin, $\&$ Cooperrider, 2015). The relationship between RC and AI could easily be assessed by focusing on the following statement of Cooperrider, Whitney and Stravos (2003);

"The use of AI builds on the positive core of the organization and assists both leaders and rank and file employees in co-creating shared organizational values and opportunities for relational improvement" (p. 4).

It is very much clear from the above statement that AI helps organizations in improving their relational capital. During literature search, it was found that very few studies were published showing AI's effectiveness in building relational capital. 
These studies carried out by Miller, Fitzgerald, Preston, \& Murrell (2002); Miller, Fitzgerald, Murrell, Preston, \& Ambekar (2005); and Bushnell, Bergthold, and Agger-Gupta (2002) highlight how relational capital could be developed through appreciative inquiry. The findings and results of these studies clearly indicate that relational capital of an organization is particularly enhanced by using interventions based on the principles of appreciative inquiry.

Several other studies have also emphasized the application of AI in the development of RC (e.g. Boyd \& Bright, 2007; Miller et al., 2005; Miller et al., 2002; Stavros et al., 2015 etc). Stavros et al. (2015), for example, explain that AI is a co-operative and co-evolutionary search for the best in people, their organizations, and the environment in which they operate. So, by carrying forward this argument, it could be inferred that in AI the main focus is on 'what is working well'. In the current study, as identified by the participants, it is their relational capital which is working well and have enabled them to compete in the market. Therefore, based on the recommendations of researchers such as Bushnell et al (2002) and Stavros et al. (2015) as well as the results of our own interventions for affirmative topic selection, this study aims at accentuating $\mathrm{RC}$ with $\mathrm{AI}$ intervention.

\section{Methodology}

The primary objective of this action-based study was to develop the relational capital of a cement manufacturing company through the application of Appreciative Inquiry. $\mathrm{AI}$ is a type of action research with social constructionist methodology that emphasizes a link between discourse, deliberation and action (Van der Haar \& Hosking, 2004; Grant, 2007; Lewis, Passmore \& Cantore, 2008). According to Leeds-Hurwitz (2009) social constructionist approach is all about the development of co-constructed understandings of the world that provides the foundations for shared assumptions regarding reality. So, AI has also the philosophical and theoretical underpinnings in the notion that aims to account for the ways in which phenomena are socially constructed (Lewis et al., 2008).

In this action research, the approach of appreciative inquiry was used as research methodology. According to Grant and Humphries (2006), AI being a research method and having an emphasis on positive attributes of organization could help in expediting organizational change. Dick (2004) argued that application of AI as OD intervention has shown a dramatic increase in recent years. The scope of $\mathrm{AI}$ as an action research method ranges from inquiries of limited scope such as change management in a school (Van Buskirk, 2002) or community (Ryan, Soven, Smither, Sullivan, \& Van Buskirk, 1999) to larger project of establishing global inter-faith organization such as the United Religions Initiative (Gibbs \& Mahe, 2003). 
The current study was carried out in contrived organizational settings with moderate degree of interference by researchers. The site for research was XYZ Cement Manufacturing Company, Pakistan. The company selected for our AI intervention was listed on Pakistan Stock Exchange (PSX). It was operating at large scale with 518 regular employees and sales revenue of more than US \$30 million. According to the company's published financial statements, it has earned a gross profit of $\$ 12$ million in the same year with the production of 0.5 million metric tons, whereas; 32,000 metric ton of its products have been exported to the neighboring countries.

Four graduate level students were also engaged to facilitate the authors in this OD intervention. The sample size was kept smaller because of the characteristics of AI and qualitative and applied nature of the study. According to Sandelowski (1995), sample size in qualitative studies totally depends upon the particular research method, purpose of sampling, and the research product intended. Among a total of 518 employees, only 26 were engaged in the inquiry because of the nature of their job (i.e. they belonged to procurement and sales departments). The study was carried out by involving participants in the 4-D cycle of AI. (i.e. Discovery, Dream, Design, and Destiny). All the five principles (Whitney, 1998) of AI were accounted for during the inquiry.

Relational capital is operationalized by referring it to the number of transactions with the stakeholders like suppliers, partners and customers. A series of activities were carried out during a period of four months (from June 01, 2017 to September 30, 2017) which included in-depth interviews for affirmative topic selection, appreciative interviews for discovery phase, generative dialogue during dream stage, formation of action groups in design phase, and incremental shifts in routines during destiny phase.

Table 1: Appreciative Inquiry Sessions

\begin{tabular}{|c|c|}
\hline Stage & Methods Used \\
\hline Affirmative Topic Selection & In-depth interviews \\
\hline Discovery & Appreciative Interviews \\
\hline Dream & Generative Dialogue \\
\hline Design & Formation of Action Groups \\
\hline Destiny & Incremental shifts in routines \\
\hline
\end{tabular}

\section{Results and Discussion}

The AI resource pack developed by the Scottish Social Service Council (SSSC) and NHS Education for Scotland (NES) was used as a guide for applying AI as research methodology. Moreover, the study carried out by Miller et al. (2005) in which 
transcultural strategic alliance was built between a U.S. multinational firm and an Indian family business through AI, was also consulted for guidance in designing organizational development intervention for this study.

The entire inquiry consisted of five sessions: four sessions were dedicated for $4 \mathrm{Ds}$ while first session was for affirmative topic selection. Researchers and participants were given a separate and well-equipped room having facilities of multimedia projectors, white boards, etc. by the top management of the cement manufacturing company. For creating understanding with participants, icebreaker session was conducted. The $4 \mathrm{D}$ cycle of $\mathrm{AI}$ is as follows:

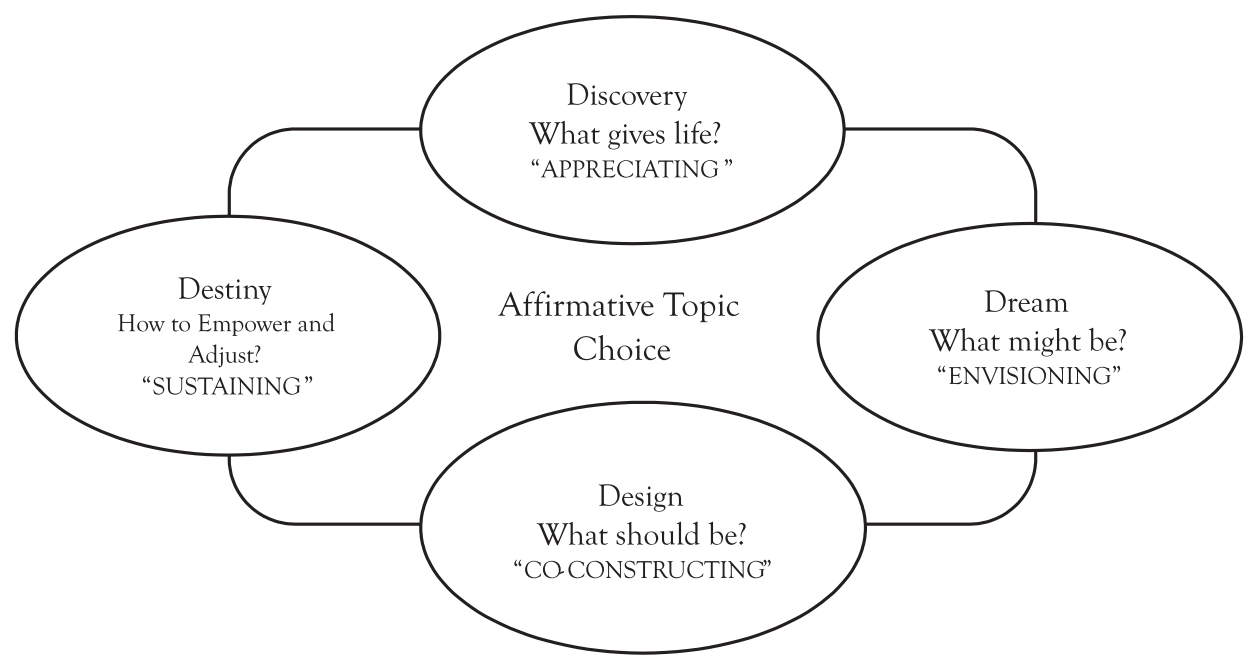

Figure 1: 4D Process of AI (Cooperrider et al., 2005)

\subsection{AI topic selection}

The first session started with an introduction to appreciative inquiry using power point presentation of 30 minutes. Afterwards, the queries and reservations of the participants regarding AI were thoroughly addressed in the session. In-depth interviews were conducted in which key position holders from top management as well as the participants of the study were asked open-ended questions about their positive core/s. In this session, practice of thinking and remembering the best work experiences was also performed. After in-depth interviews with participants, they were called upon for focus group discussion and a consensus on the AI topic was developed. At the end of first session, participants reviewed the mapping and graphic representation of concepts which were developed during the focus group discussion. It is worth noting here that relational capital was not determined by the researchers as an affirmative topic for appreciative inquiry. It was selected by the participants themselves, as they 
perceived it as the strength of their organization as well as an essential element for organizational survival. During the selection of affirmative topic, three key position holders from top management were also involved in the process.

Most of the participants were of the opinion that better organizational performance is the result of their relations across the supply chain (SC). They termed themselves better than other competing firm in the same industry in this regard. As the main purpose of appreciative inquiry is to help an organization in capitalizing its strengths (Cooperrider et al., 2003), so accordingly relational capital was selected as the topic for this study. The positive core or the affirmative topic selection for this inquiry was based on the motto, "Stronger and deeper Relational Capital of our organization". After setting AI topic, a comprehensive plan was prepared for 4D-Cycle of Discovery, Dream, Design and Destiny Stages.

\subsection{Discovery stage}

During the discovery phase, participants were engaged and probed by asking positive and open-ended questions. All the participants were divided into dyadic groups (group having two members) and were requested to reflect on the events when they felt that their organization had the best relational capital. Dyads were then reunited into the larger group of all members wherein they shared their reflections in the form of story/ies. According to Ludema (2002), storytelling has significant effect on organizational life as it helps in creating organizational reality.

In discovery stage, participants noted down all of their best work experiences where they felt it worked well for the organization in building its relational capital. They also jotted down the reasons or locomotives for these best past work experiences. Some of the questions that were asked during discovery stage are as follows:

- What has been one of your best experiences of dealing with your customers and suppliers?

- What is really important about this experience? What do you value the most?

- What made this experience possible?

- When things are working at their best in maintaining relations with customers and suppliers, what does it look or feel like?

Furthermore, all the participants were asked to make a wish (in writing) for their organization's relational capital. In the last segment of the first session, feedback about whole session was taken from the participants by asking question, "What are you taking home from today's session?" 
The main output of this stage was having a list of life-giving activities of the organization. Participants reported their best work (life-giving) experiences in story format by reminding each other the exact things happenings in the events. For instance, a group illustrated their best experience by quoting that their existing customers recommended the company's product to other potential customers. Similarly, they also highlighted few big customers with whom they had retained their business for a long time. In the same way, they also pointed out some suppliers who had supplied them the raw material in very short span of time. A participant reminded other group members of the technical guidance given to them by one of the suppliers. In a similar vein, participants mentioned some very practical and productive suggestions from customers regarding the distribution channel of the company.

While speaking about the relations among employees of the organization, a participant expressed "Mong khu tol sara malghari yo, pa khpal maanz ky mu deir kha taluqaat de" which translates as "we all are friends and we have very good relations with one another". During the intervention, it was observed that actually they do have good relations among them and a high level of coordination and support was witnessed among them.

\subsection{Dream stage}

With a gap of two weeks, third session was started with a short welcome note and a brief reconnect to appreciative inquiry activity. The purpose was to reconnect appreciative thinking and re-emphasizing on the role of positive experiences in better future performance as well as building and maintaining strong relational capital. An extensive exercise for executing the second D i.e. "Dream" was carried out. The main technique used here was the generative dialogue among the groups of the participants. They were asked to dream freely for the betterment of relational capital in their organization.

Before initiating dream stage, some success stories of national and international entities were presented before the participants. Especially the case of Starbucks (an American Coffeehouse chain) as presented by Gulati, Huffman and Neilson (2002), in which the company had transformed itself by utilizing its relational capital, was shared with participants. The role of relational capital in the success of these organizations was highlighted and stressed upon by sharing these case studies. After that participants were grouped in the team of 4 members, and were asked to envision how relational capital would appear to be, if those peak moments of RC identified in discovery stage would have happened more often. Further, the participants were asked to imagine their relational capital $2-3$ years from the point of discussion, with significant experiences occurring at a higher frequency. They were also involved in the activity of creating a representation of future relational capital through pictures, 
sketches, slogans, and drawings. At the end of dream stage, all the groups involved in the activity were asked to share their dreams with one another. They were also asked, "What are the enablers for your dream?"

It is worth mentioning that in this stage, researchers/ authors noted that the participants were emphasizing more on relations with suppliers and distributors while ignoring the other aspects of RC i.e. relationships with customers and employees. So, researchers purposely reminded them these two important aspects and acquired their insights on the relations with customers and the relations among the employees of the company. In response, some of the participants dreamed really big. They proposed to have shared offices through virtual networks with all the stakeholders. Relationship with suppliers was dreamt to be based on just in time (JIT) approach. Profit sharing with suppliers and distributors was also shared as their dream. Fair pricing practice (maintaining lowest prices in the industry) was also suggested for better relations with customers. They also dreamt that they could have help by their existing suppliers in extending their relations to other forces working in the same industry. For getting the confidence and trust of suppliers and distributors, the participants recommended that they should also be included in our marketing campaigns.

\subsubsection{Enablers}

When participants were asked about the enablers for their dreams, they named several elements. Firstly, and the most frequently mentioned enabler was the top management support and their encouragement for more communication with supply chain members. As a participant quoted

"Organizational success and relational capital go hand in hand. It requires a great deal of energy and time to establish productive relations across the supply chain. If top management gives us free hand in dealing with our suppliers and customers then we can make real change and without their support we cannot capitalize on available business opportunities".

The second most expressed/quoted enabler was decentralized decision making and empowerment of middle management. Participants opined that in certain domains they needed instant decision making to run their business smoothly. According to a participant,

"For dealing with our customers and the other members of supply chain properly, all we (middle management) need is the empowerment in decision making domain."

Third most highlighted enabler was easy access to required resources. Participants were of the opinion that if they were granted full access to required resources, it would 
help them in boosting the organization's relational capital by timely responding to customers' orders and queries. Similarly, they also emphasized the importance of this enabler in dealing with other stakeholders like distributors and suppliers.

Fourth enabler was frequent interactions with supply chain members. Participants expressed that the more employees interact and socialize with their supply chain members, the more will they understand each other. "Meeting in-person with the supply chain members will keep us updated about the current market situation", a participant reported. The idea of connecting with suppliers, distributors and customers through social media especially facebook and whatsapp was also stressed upon by some of the participants.

Some other enablers were also elicited by the respondents, in which the important were: representation of supply chain members in board of directors, inviting major customers in company's ceremonies, monthly social gatherings with various stakeholders etc.

\subsection{Design stage}

During design stage, groups having four members each were made and were named as action groups. Then a second wave of focus group discussion was conducted to list down the ideas for transforming the existing practices for the enrichment of relational capital. A bulky list of ideas was posted and then the participants were asked to group the ideas into common categories. For getting relevant ideas and refraining participants from losing track, the following model of relational capital was displayed

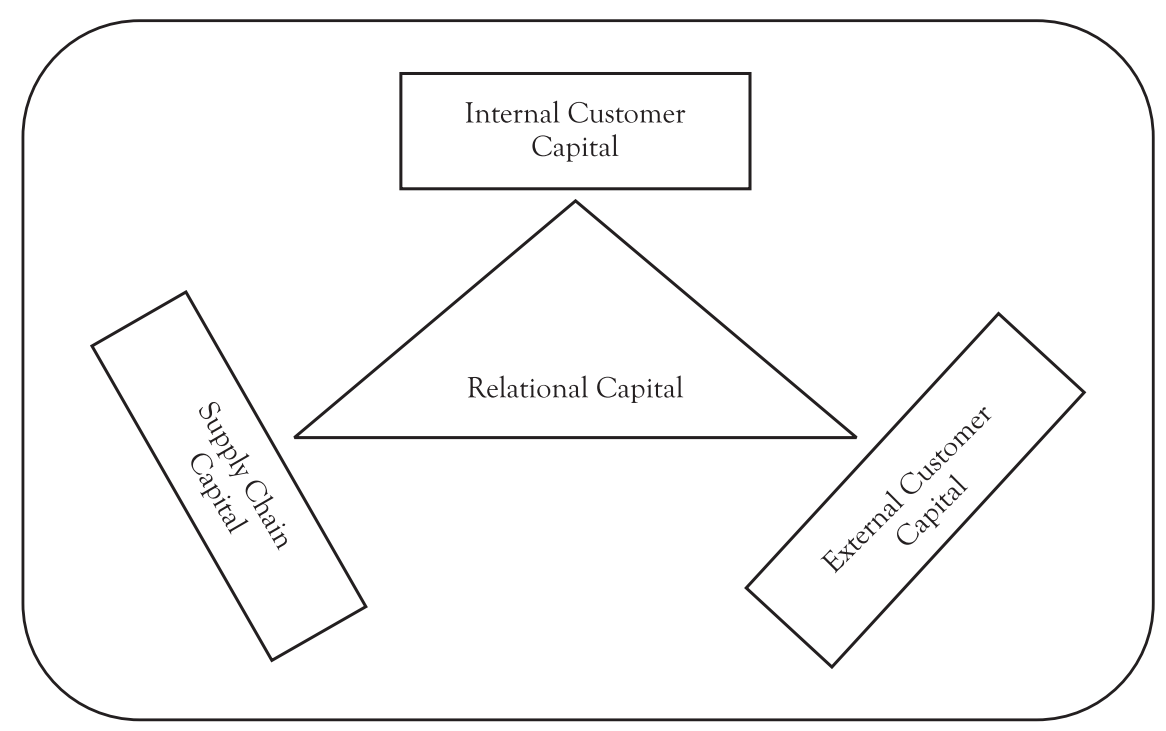

Figure 2: Relational Capital (Redefined) 
on multimedia. This model was developed from extensive review of literature and by grouping the ideas of participants.

In the next step, participants narrowed down the categories for goals that would facilitate the desired change in RC. Participants were given the task of creating an action plan for each goal and prioritizing them in descending order. After developing action plans, third wave of focus group discussion was conducted in which agreement on goals and action plan was developed.

\subsubsection{Roughly categorized ideas from Design Stage}

1. Ensure continuous commitment and efforts to develop networks, trust and collaboration among members of supply chain;

2. Create a shared vision, direction, and understanding for better relational capital

3. Establish project goals, expectations and agreements, as well as frequent reviews of progress

4. Communicate freely and frequently across the supply chain and also within the departments of the organization in the form of morning meetings

5. Plan frequent visits to partners' business sites

6. Deal with complex issues jointly and proactively

7. Build close relationships and provide a sense of belongingness to stakeholders

8. Clearly articulate the policy of profit sharing in collaborating efforts of supply chain members

9. Define accountable roles and responsibilities based on competencies for each partner

10. Appreciate and respect different cultures and ways of doing business of the partners

11. Ensure representation of customers, suppliers, and other stakeholders in strategic decisions of the company

12. Realize and accept that there will be conflict in the interests of supply chain members

13. Ensure the delivery of product at the doorstep of big customers (Thekaydars i.e. builders/contractors) 
14. Provide packaging as per customers' specification

15. Appreciate long term customers by giving them awards/certificates

16. Encourage customers retention

17. Provide better customer service

18. Develop and understanding of the needs of customers

19. Make arrangements for distributors and customers to visit supply sites, if desired

20. Plan company officials' visit to construction sites

21. Use social media for linking with stakeholders

22. Create a culture of informal dispute resolution (Jirga system)

23. Plan joint R\&D efforts with stakeholders

24. Use multiparty quality audits/ 360 degree feedback for quality improvement

25. Introduce flexible collection and payment procedures across the supply chain

26. Implement Just-in-Time approach across the supply chain

27. Promote the culture of knowledge sharing across supply chain

28. Share new business ideas, know-how, and technologies with supply chain members

29. Avoid switching partners, value long term relations

30. Recognize of the efforts of individual members

31. Ensure resource sharing across supply chain

32. Hold joint brainstorming sessions for identification of new business opportunities

33. Celebrate success together.

\subsection{Destiny stage}

In destiny stage, participants were allowed to make incremental shifts in their work routines. Every possible effort was made to implement all the aspects of action plan developed during design stage. The top management and the middle management were requested to encourage their employees for making more and more contacts with customers and suppliers. 
Ideas from Design Stage

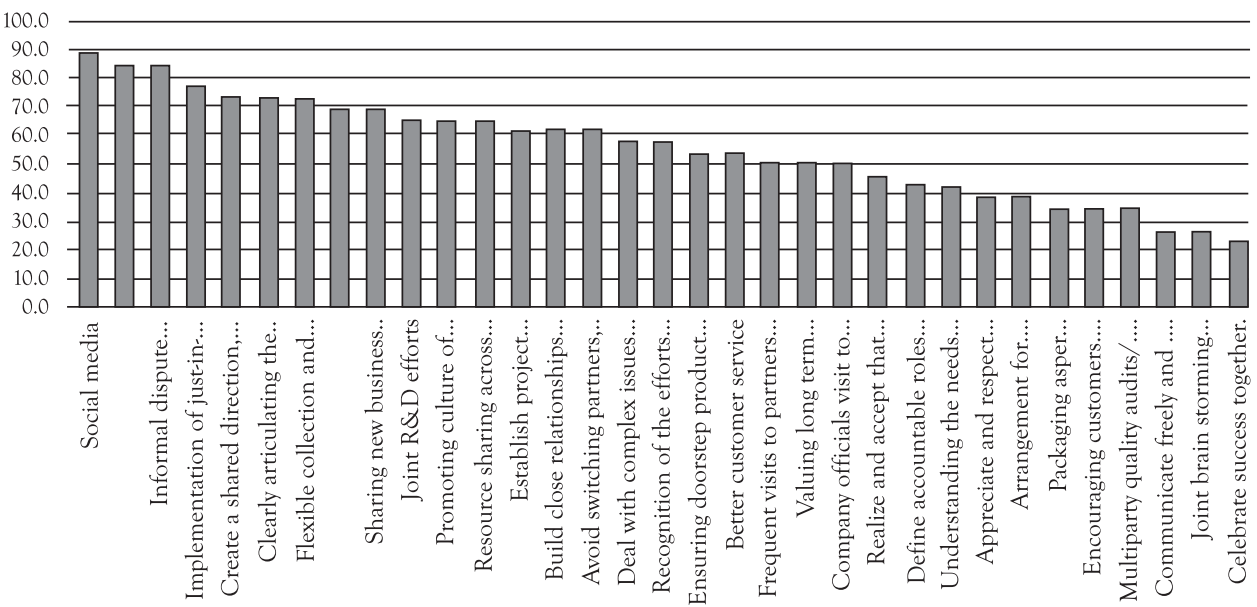

Figure 3: Graph Showing the Frequency of Ideas

In this stage, the role of researchers was very limited and all the responsibility of implementation of action plan was handed over to the management of the selected cement manufacturing company. Among the participants, one member each from procurement department and sales department was made the focal person for monitoring the progress on the implementation of action plan and reporting the same to the researchers. Goals of the intervention were evaluated after two months of intervention. Focus group sessions were conducted with top and middle management as well as the participants to evaluate their progress on each goal of action plan. Conclusions were drawn, and new knowledge established on relation capital management was shared with the intervention team. Recommendations were made for the next AI theme and cycle for future interventions.

\subsubsection{Incremental shifts in Routine}

As shown in figure 2, $\mathrm{RC}$ was taken as the combination of three capitals i.e. supply chain capital, internal customer capital, and external customer capital. For each dimension of RC, the participants have developed and implemented some incremental changes in their routines.

For improving their SC capital, they launched a relatively stronger and bigger marketing and publicity campaign by involving SC members in it. Participants started frequent telephonic conversations with SC members, asking about the market situation and expected demand from customers. They all decided to make the habit of timely response to suppliers, distributors and customers and sectional heads offered small rewards for such behavior by employees and recommended this behavior to be 
added into key performance indicators (KPIs) of employees. The employees begun to use social media for better relations with the SC members and providing them the opportunity of interactive communication with higher degree of ease and comfort. The suggestion for collective board of directors, where more stakeholders will be on board, was placed before top management. The purpose was to ensure decision making collectively and providing opportunity to each individual for representing themselves and their business interests.

For improving their internal customer capital, they embarked on daily morning meeting of 15 minutes (approximately) within each department. The main purpose of these meetings was to have greater socialization opportunities as well as to have a shared understanding of "to do" list of the day. Moreover, cross functional teams were utilized to address adhoc operational issues which would be helpful for improving inter-departmental relations across the company.

Dealing with external customer capital, customers' complaints were handled on priority basis. They also attempted to increase the effectiveness of public relations department by having more and more publicity and media and community relations. Employees of the company were encouraged to have personal relations with suppliers, distributors, and customers by middle and top management by offering them small incentives.

\section{Implications for Practice}

In this four months long endeavor, researchers uncovered some interesting facts about AI. Firstly, appreciative inquiry was unknown and a very novel (but exciting) activity for all the participants. In the beginning, they were very reluctant to participate because of the word "inquiry". As a matter of fact, in Pakistani context, mostly inquiries are initiated after any incident not desirable for the top management. First day of the intervention was dedicated to clarifying the concept of AI to the participants. Their doubts and ambiguities were removed by introducing AI to them through multimedia presentation which was accompanied by the narration of success stories of $\mathrm{AI}$ as $\mathrm{OD}$ intervention across the globe (as has been mentioned in previous section). Secondly, some participants were not expressing their full interest in the activity but slowly and gradually, they were won over and were made fully involved into the AI intervention. For making AI sessions more attractive and engaging, the session venue was decorated with captivating posters and flip charts. Moreover, the participants were offered complimentary food and beverages during lunch and tea breaks.

Thirdly, for creating harmony between the participants and authors, icebreaker session at the start of intervention was of significant use. Participants' chairs were 
arranged in a circular shape and they were asked to give the introduction of the person sitting at their right side. This helped in creating friendlier environment as some participants used the (funny but not disrespectful) nicknames for their colleagues. The authors/ researchers also introduced themselves in the same manner to develop concordance with the participants. Therefore, it is recommended that such icebreaker sessions should be made a part of each AI intervention. As in training sessions, icebreakers could also be used at other stages of AI intervention where researchers may find that participants are losing focus and interest in session. Fourthly, participants were found to be more relaxed in informal environment, and as the intervention proceeded through, more and more cohesion among the participants was observed. There were more exchanges of friendly gestures among the participants as the intervention moved towards its completion. For future studies, therefore, it is recommended that more flexible and informal AI interventions should be designed based on the respective organization's values and culture.

Fifthly, the participants showed their interest in organizing more OD activities as it could help them in avoiding the boredom due to monotony and routineness of job. They expressed joy because they were doing something other (fruitful) than their routine job activities. Therefore, it is recommended that such activities should be organized after a reasonable period of time to have fresh insights from employees and to provide them with the opportunity of expressing their opinion. Sixthly, during dream stage participants were focusing more on suppliers and distributors while ignoring customers and the employees. When reminded about these two important aspects of RC, they provided their ideas accordingly. This showed the narrow and localized approach adopted by participants towards understanding the concept of RC. Thus, AI researchers should focus on identifying the signals and if there is anything that the participants are missing, it should be introduced by the researchers themselves.

Lastly, the study highlights that appreciative inquiry interventions could help the managers in accentuating the role of relational capital, which has been identified in the literature as an important element to gain competitive advantage. AI as organizational development intervention in manufacturing sector organizations of Pakistan could also help practitioners to provide their employees with an opportunity to actively participate in organizational affairs especially in setting strategic direction and decision making. Moreover, practitioners could also get benefit of it by creating a culture of knowledge sharing, creativity and innovation in their organizations. It is evident from the findings of our study that AI could help an organization in building its relational capital. Therefore, practitioners could strengthen their organizations by conducting AI intervention for other strategically important issues. Similarly, it is recommended to the managers of manufacturing sector organizations to place more 
emphasis on the development of effective relational capital across their supply chains, which would help them in improving their business performance.

\section{Conclusion}

AI is not a panacea which could cure all illness but helps in providing a way forward and new insights stimulated from collaborative research in a specific area of organizational development (Carter, 2006). Aswering the question that what is the outcome of this AI?, authors would quote the parameter defined by Bushe and Kassam (2005) whether AI has brought new knowledge or new process? The answer, in case of this intervention, is both the new knowledge and the new processes. According to Hammond and Royal (2001) and Raymond and Hall (2008), the end point/output of any appreciative inquiry is the construction of positive vision to amplify what is working. This view is further strengthened by the argument of Bushe (2007), which declared that AI doesn't always focus on positives but on the things that could generate a better future. The results of our AI intervention, explain that participants were already aware of the importance of relational capital but how this RC could be revitalized and rejuvenated for the better performance of their organization, is new knowledge that the study participants as well as top management gained from this intervention. Participants themselves identified the important activities that could boost their relational capital across supply chain. Moreover, they showed their interest in future $\mathrm{OD}$ interventions in the other units of organization.

Post-intervention visits to the company revealed significant improvement in the relational skills of the employees of sales and procurement department within a short span of three months after the intervention. Top management also affirmed that considerable changes occurred after the AI sessions. The attitude of employees in dealing with supply chain members and customers has softened and improved and the better intra-organizational communication among the employees has also been reported.

For future studies, it is recommended that the supply chain members and customers may also be included in the AI sessions to have a more comprehensive picture of $\mathrm{RC}$ of an organization. Joint sessions of all the stakeholders would be helpful in understanding the concerns of all and would result in establishing and maintaining more effective collaborative relations. Similarly, the strategic decisions of company could easily be communicated to the rest of the stakeholders in joint intervention sessions.

\section{References}

Agostini, L., \& Nosella, A. (2017). Enhancing radical innovation performance through intellectual 
capital components. Journal of Intellectual Capital, 18(4), 789-806.

Ahmed, M. U., Kristal, M. M., \& Pagell, M. (2014). Impact of operational and marketing capabilities on firm performance: Evidence from economic growth and downturns. International Journal of Production Economics, 154(8), 59-71.

Bernstein, S. D. (2003). Positive organizational scholarship: Meet the movement An interview with Kim Cameron, Jane Dutton, and Robert Quinn. Journal of Management Inquiry, 12(3), 266-271.

Bharadwaj, A. S. (2000). A resource-based perspective on information technology capability and firm performance: An empirical investigation. Management Information Systems Quarterly, 24(1) 169-196.

Black, W. R., Burrello, L. C., \& Mann, J. L. (2017). A new framework for leadership preparation. NASSP Bulletin, 101(1), 50-71. https://doi.org/10.1177/0192636517698567

Bontis, N. (1998). Intellectual capital: An exploratory study that develops measures and models. Management Decision, 36(2), 63-76.

Bontis, N. (1999). Managing organizational knowledge by diagnosing intellectual capital: Framing and advancing the state of the field. International Journal of Technology Management, 18(5), 433-463.

Boyd, N. M., \& Bright, D. S. (2007). Appreciative inquiry as a mode of action research for community psychology. Journal of Community Psychology, 35(8), 1019-1036.

Bueno, E., del Real, H., Fernandez, P., Longo, M., Merino, C., Murcia, C., \& Salmador, M. P. (2011). Intellectus Model for the measurement, management and information of intellectual capital. IADE, Universidad Autonoma de Madrid, Madrid.

Bushe, G. (2007). Appreciative inquiry is not about the positive. OD Practitioner, 39(4), 30-35.

Bushe, G. (2012). Feature choice by Gervase Bushe Foundations of Appreciative Inquiry: History, criticism and potential. AI Practitioner, 14(1), 76-89.

Bushe, G. (2013). Generative process, generative outcome: The transformational potential of appreciative inquiry. In D. L. Cooperrider, D. P. Zandee, L. N. Godwin, M. Avital, \& B. Brodie (Eds.), Organizational generativity: The appreciative inquiry summit and a scholarship of transformation (pp. 89-113). Bingley: Emerald Group Publishing Limited.

Bushe, G., \& Kassam, A. F. (2005). When is appreciative inquiry transformational? The Journal of Applied Behavioral Science, 41(2), 161-181.

Bushnell, D., Bergthold, K., \& Agger-Gupta, N. (2002). Building social capital and organizational capacity in community-based nonprofit organizations through appreciative inquiry. OD Practitioner, 34(4), 14-19.

Capello, R., \& Faggian, A. (2005). Collective learning and relational capital in local innovation processes. Regional Studies, 39(1), 75-87. 
Carlsen, A., Rudningen, G., \& Mortensen, T. F. (2014). Playing the cards: Using collaborative artifacts with thin categories to make research co-generative. Journal of Management Inquiry, 23(3), 294-313.

Carter, B. (2006). One expertise among many- working appreciatively to make miracles instead of finding problems. Journal of Research in Nursing, 11(1), 48-63.

Chen, C. J., Liu, T. C., Chu, M. A., \& Hsiao, Y. C. (2014). Intellectual capital and new product development. Journal of Engineering and Technology Management, 33(2), 154-173.

Cheng, C. C., \& Huizingh, E. K. (2014). When is open innovation beneficial? The role of strategic orientation. Journal of Product Innovation Management, 31(6), 1235-1253.

Clercqa, D., \& Sapienzab, H. J. (2006). Effects of relational capital and commitment on venture capitalists: Perception of portfolio company performance. Journal of Business Venturing, 21(1), 326-347.

Cooperrider, D. L., \& Whitney, D. (2005). Appreciative inquiry: A positive revolution in change. San Francisco, CA: Berrett-Koehler Publishers.

Cram, F. (2010). Appreciative inquiry. MAI Review, 2010(3), 1-13.

Curtis, K., Gallagher, A., Ramage, C., Montgomery, J., Martin, C., Leng, J.,... Wrigley, M. (2017). Using Appreciative Inquiry to develop, implement and evaluate a multi-organization "Cultivating Compassion" programme for health professionals and support staff. Journal of Research in Nursing, 22(1-2), 150-165.

Datta, S., K., \& De, T. (2017). Role of Relational Capital and Firm Performance: Analysis of a Cluster of Bell-metal Enterprises in a Rural Region in West Bengal, India. Journal of Entrepreneurship $\mathcal{E}$ Organization Management, 6(1), 1-6.

Delgado, M. (2011). The role of intellectual capital assets on the radicalness of innovation: direct and moderating effects (UAM-Accenture Working Papers No. 5). Madrid: Autonomous University of Madrid.

Dick, B. (2004). Action research literature: Themes and trends. Action research, 2(4), 425-444.

Elliott, C. (1999). Locating the energy for change: An introduction to appreciative inquiry. Winnipeg, MB: International Institute for Sustainable Development.

Finegold, M. A., Holland, B. M., \& Lingham, T. (2002). Appreciative inquiry and public dialogue: An approach to community change. Public Organization Review, 2(3), 235-252.

Gabrielsson, M. (2005). Branding strategies of born-globals. Journal of International Entrepreneurship, 3(3), 199-222.

Gibbert, M., Leibold, M., \& Voelpel, S. (2001). Rejuvenating corporate intellectual capital by co-opting customer competence. Journal on Intellectual Capital, 2(2), 109-126.

Gibbs, C., \& Mahé, S. (2003). Birth of a global community: Appreciative inquiry in action. Euclid, OH: Lakeshore Communications. 
Gogan, M., Duran, D. C., \& Draghici, A. (2014). The impact of relational capital on competitiveness of the organization. Network Intelligence Studies, 2(4), 233-240.

Grant, S. (2007). Learning through being and doing. Action Research, 5(3), 265-274.

Grant, S., \& Humphries, M. (2006). Critical evaluation of appreciative inquiry: Bridging an apparent paradox. Action Research, 4(4), 401-418.

Gulati, R., Huffman, S. \& Neilson, G (2002). The Barista Principle: Starbucks and the Rise of Relational Capital. Strategy + Business, 2002(28). Retrieved from https://www.strategy-business.com/ article/20534?gko=eb786

Hammond, S., \& Royal, C. (2001). Lessons from the field: Applying appreciative inquiry (Revised ed.). Plano, TX: Thin Book Publishing.

Hormiga, E., Batista-Canino, R. M., \& Sánchez-Medina, A. (2011). The impact of relational capital on the success of new business start-ups. Journal of Small Business Management, 49(4), 617-638.

Hsu, L. C., \& Wang, C. H. (2012). Clarifying the effect of intellectual capital on performance: The mediating role of dynamic capability. British Journal of Management, 23(2), 179- 205.

Hsu, Y. H., \& Fang, W. (2009). Intellectual capital and new product development performance: The mediating role of organizational learning capability. Technological Forecasting and Social Change, 76(5), 664-677.

Kale, P., Singh, H., \& Perlmutter, H. (2000). Learning and protection of proprietary assets in strategic alliances: Building relational capital. Strategic management journal, 21(3) 217-237.

Kaye Hart, R., Conklin, T. A., \& Allen, S. J. (2008). Individual leader development: An appreciative inquiry approach. Advances in Developing Human Resources, 10(5), 632-650.

Leeds-Hurwitz, W. (2009). Social construction of reality. In S. W. Littlejohn \& K. A. Foss (Eds.), Encyclopedia of communication theory. (pp. 892-895). Thousand Oaks, CA: SAGE Publications. doi:10.4135/9781412959384.n344

Lenart-Gansiniec, R. (2016). Relational capital and open innovation - in search of interdependencies. Procedia - Social and Behavioral Sciences, 220(March), 236-242.

Lewis, S., Passmore, J., \& Cantore, S. (2008). Using appreciative inquiry in sales team development. Industrial and Commercial Training, 40(4), 175-180.

Lowendahl, B. (2005). Strategic management of professional service firms. Denmark: Copenhagen Business School Press.

Ludema, J. D. (2002). Appreciative storytelling: A narrative approach to organization development and change. In R. E. Fry, D. Whitney, J. G. Seiling \& F. Barrett (eds.), Appreciative inquiry and organizational transformation: Reports from the field. (pp. 239-261). West Port, CT: Greenwood Publishing. 
Ludema, J. D. Whitney, D., Mohr, B. J. \& Griffen, T. J. (2003). The appreciative inquiry summit. San Francisco, CA: Berret-Koehler.

Maritz, G. U., \& Coetzee, M. (2012). Creative Synergy: Using community theatre and appreciative inquiry for young people's critical participation in HIV prevention and education. Youth Theatre Journal, 26(1), 133-145.

Martín de Castro, G., López Sáez, P., \& Emilio Navas López, J. (2004). The role of corporate reputation in developing relational capital. Journal of Intellectual Capital, 5(4), 575-585.

Meritum, P. (2002). Guidelines for managing and reporting on intangibles (Intellectual Capital Report). Madrid: Vodafone Foundation.

Miller, M. G. (2000). Case study of building relational capital in a transcultural strategic alliance. Doctoral dissertation, Pepperdine University, California, USA.

Miller, M. G., Fitzgerald, S. P., Murrell, K. L., Preston, J., \& Ambekar, R. (2005). Appreciative inquiry in building a transcultural strategic alliance: The case of a biotech alliance between a US multinational and an Indian family business. The Journal of Applied Behavioral Science, 41(1), 91-110.

Miller, M. G., Fitzgerald, S. P., Preston, J. C., \& Murrell, K. L. (2002). The efficacy of appreciative inquiry in building relational capital in a transcultural strategic alliance. Academy of Management Proceedings, 2002(1), E1-E6.

Nold III, H. A. (2012). Linking knowledge processes with firm performance: organizational culture. Journal of Intellectual Capital, 13(1), 16-38.

Pedler, M., \& Burgoyne, J. G. (2007). From PRA to PLA and pluralism action learning. In P. Reason, $\&$ H. Bradbury (Eds.), The SAGE handbook of action research. London: Sage Publications.

Prahalad, C. K., \& Ramaswamy, V. (2000). Co-opting customer competence. Harvard Business Review, 78(1), 79-90.

Raymond, E. M., \& Hall, C. M. (2008). The development of cross-cultural (mis) understanding through volunteer tourism. Journal of Sustainable Tourism, 16(5), 530-543.

Reed, K. K., Lubatkin, M., \& Srinivasan, N. (2006). Proposing and Testing an Intellectual Capital-Based View of the Firm. Journal of Management Studies, 43(4), 867-893.

Ryan, F. J., Soven, M., Smither, J., Sullivan, W. M., \& VanBuskirk, W. R. (1999). Appreciative inquiry: Using personal narratives for initiating school reform. The Clearing House, 72(3), 164-167.

Sandelowski, M. (1995). Sample size in qualitative research. Research in Nursing $\mathcal{E}$ Health, 18(2), 179-183.

Shah, H. A., Yasir, M., Majid, A., \& Javed, A. (2019). Impact of networking capability on organizational survival of SMEs: Mediating role of strategic renewal. Pakistan Journal of Commerce and Social Sciences (PJCSS), 13(3), 559-580. 
Shah, H. A., Yasir, M., Majid, A., Yasir, M. \& Javed, A. (2019). Promoting strategic performance through strategic orientation and strategic renewal: A moderated mediation model. Management Decision, 58(2), 376-392.

Sim, J. H. (2019). Exploring the Relational Leadership Potential of Appreciative Inquiry: A Case Study. South Asian Journal of Business and Management Cases, 8(1), 47-57.

Simons, M., \& Havert, M. L. (2012). Using appreciative inquiry to support a culture shift in transition, Technical Services Quarterly, 29(3), 207-216.

Somerville, M. M., \& Farner, M. (2012). Appreciative inquiry: A transformative approach for initiating shared leadership and organizational learning. Revista de Cercetare si Interventie Sociala, 38(September), $7-24$.

Sorensen, P. F., Yaeger, T. F., \& Bengtsson, U. (2003). The promise of appreciative inquiry: A 20-year review. OD Practitioner, 35(4), 15-21.

Stavros, J. M., Godwin, L. N., \& Cooperrider, D. L. (2015). Appreciative inquiry: Organization development and the strengths revolution. In W. J. Rothwell, J. M. Stavros \& R. L. Sullivan (Eds.), Practicing organization development: Leading transformation and change. (pp. 96-116). Hoboken, NJ: Wiley.

Subramaniam, M., \& Youndt, M.A., (2005). The influence of intellectual capital on the types of innovative capabilities. Academy of Management Journal, 48(3), 450-463.

Theoharakis, V., Sajtos, L., \& Hooley, G. (2009). The strategic role of relational capabilities in the business-to-business service profit chain. Industrial Marketing Management, 38(8), 914-924.

Trotta, A., Iannuzzi, A., Cavallaro, G., \& Dell'Atti, S. (2011). Banking reputation and CSR: A stakeholder value approach. In E. Gummesson, M. Cristina \& F. Parola (Eds.), Proceedings of The Naples Forum on Service 2011 -Agenda in Napoli, Italy. Naples Forum on Service, Giannini, Napoli (ISBN: 978-88-7431-525-3).

Uzzi, B., \& Lancaster, R. (2003). Relational embeddedness and learning: The case of bank loan managers and their clients. Management Science, 49(4), 383-399.

Van Buskirk, W. (2002). Appreciating appreciative inquiry in the urban catholic school. Appreciative inquiry and organizational transformation: Reports from the field, 67-97.

Van der Haar, D., \& Hosking, D. (2004). Evaluating appreciative inquiry: A relational constructionist perspective. Human Relations, 57(8), 1017-1036.

Westlund, H. (2003, March). Implications of social capital for business in the knowledge economy: Theoretical considerations. In Tokyo: International Forum on Economic Implication of Social Capital. Economic and Social Research Institute, Cabinet Office, Tokyo, Japan.

Whitney, D. (1998). Let's change the subject and change our organization: An appreciative inquiry approach to organization change. Career Development International, 3(7), 314-319. 
Whitney, D., \& Cooperrider, D. (2011). Appreciative inquiry: A positive revolution in change. San Francisco, CA: Barrett-Koehler Publishers.

Whitney, D., \& Gibbs, C. (2006). Appreciative inquiry. OD Practitioner, 38(4), 53-58.

Whitney, D., \& Trosten-Bloom, A. (2010). The power of appreciative inquiry: A practical guide to positive change. Berrett-Koehler Publishers. 